\title{
Evaluation of Maximum Power Point Controllers in Photovoltaic System
}

\author{
N. Drir, L. Barazane, and M. Loudini
}

\begin{abstract}
The characteristics output of solar panels are nonlinear and change with the environmental factors, so we need a controller named maximum power point tracker MPPT to extract the maximum power at the terminals of photovoltaic generator. In this study we present the two most popular controllers refers to traditional approach based on the perturbation \& observation (P\&O) methods and incremental conductance (INC). Then we explore a new intelligent controller based on fuzzy logic. The obtained results under various conditions of functioning have shown the good tracking and rapid response to change in different meteorological conditions of intelligent controller compare with the conventional one.
\end{abstract}

Index Terms-Fuzzy logic, maximum power point tracking, photovoltaic, P\&O, incremental conductance.

\section{INTRODUCTION}

Photovoltaic (PV) cells are an attractive source of energy. Abundant and ubiquitous, this source is one of the important renewable energy sources that have been increasing worldwide year by year [1].

In the V-P characteristic curve of GPV, there is a maximum point called the maximum power point (MPP). So we need a controller named maximum power point tracker MPPT to extract the maximum power at the terminals of PVG. The Two most famous one are called perturbation and observation $(\mathrm{P} \& \mathrm{O})$ controller and incremental conductance (INC).

But this method has presents limitations in their efficiency, to track maximum power point as fast as possible to reduce oscillations in output power systems [2].

In this paper, we propose to study the modeling of a photovoltaic system and to find a method for optimizing the operation of the PV generator using the new intelligent Fuzzy logic controller.

\section{Photovoltaic Power Generation}

The photovoltaic solar energy comes from the direct conversion of a portion of solar radiation into electrical energy carried through a photovoltaic cell based on physical phenomenon called photovoltaic effect. The role of this latter consists on producing an electromotive force when the surface of the cell is exposed to light [3].

Manuscript received May 24, 2014; revised July 28, 2014.

N. Drir and L. Barazane are with Faculté d'Electronique et d'Informatique, Université des Sciences et de la Technologie Houari Boumediene (USTHB), Alger, Algeria (e-mail: dr_nadia22@hotmail.com, lbarazane@yahoo.fr).

M. Loudini is with Laboratoire de Communication dans les Systèmes Informatiques (LCSI), Ecole Nationale Supérieure d'Informatique (ESI), Alger, Algeria (e-mail: m_loudini@esi.dz).
The electrical equivalent circuit of solar cell is composed of a light-generated current source, two diode, series and parallel resistance (see Fig. 1).

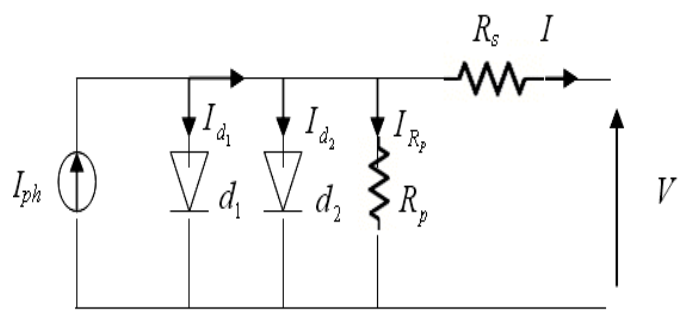

Fig. 1. Equivalent electrical circuit for the PV cell.

The equation for the current and voltage of solar cell is given by:

$$
\begin{gathered}
I=I_{p h}-I_{s 1}\left[e^{\frac{q\left(V+I R_{s}\right)}{n_{1} k T}}-1\right]-I_{s 2}\left[e^{\frac{q\left(V+I . R_{s}\right)}{n_{2} k T}}-1\right]-\frac{V+I R_{s}}{R_{P}} . \\
I_{p h}=S \cdot I_{p h \cdot \max }
\end{gathered}
$$

$S:$ Percentage of irradiation,

$I_{S 1}$ and $I_{S 2}$ : the saturation currents of the diodes,

$n_{1}$ and $n_{2}:$ purity factors of the diodes,

$R_{s}$ and $R_{p}$ are respectively the series resistance and the parallel resistance,

$T$ : Absolute temperature in Kelvin.

The equation also contains the elementary charge constant $q\left(1,602 \cdot 10^{-19} \mathrm{C}\right)$ and the Boltzmann constant $k\left(1,380 \cdot 10^{-23} \mathrm{~J} / \mathrm{K}\right)$.

$R_{s}$ and $R_{p}$ are respectively the series resistance and the parallel resistance.

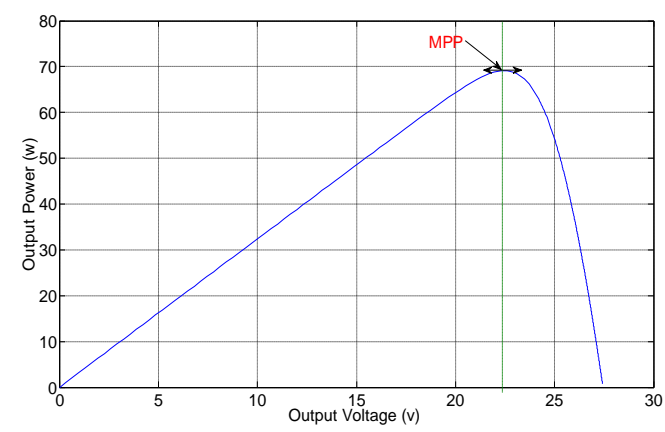

Fig. 2. Power curve under standard condition.

The association of several PV cells in series-parallel gives rise to a photovoltaic generator (GPV), which has a 
current-voltage (I-V) non linear with an operating point (MPP) which depends on the illumination level and temperature and aging of all [3].

As we can see in Fig. 2 in the output characteristics P-V of PVG there is maximum power point MPP.

Fig. 3 and Fig. 4 present the characteristics P-V for various irradiations and various temperatures.

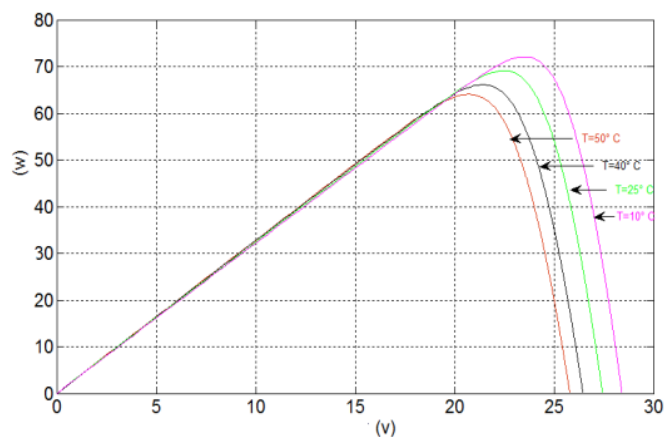

Fig. 3. Characteristic of power-voltage for different temperature

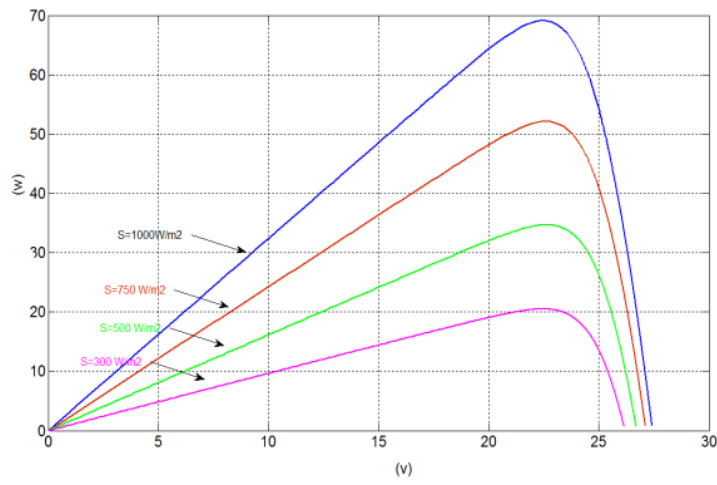

Fig. 4. Characteristic of power-voltage for different irradiation.

So in order to extract at each moment the maximum power at the terminals of PVG insertion of maximum power point tracker (MPPT) is necessary between the photovoltaic module and load (see Fig. 5).

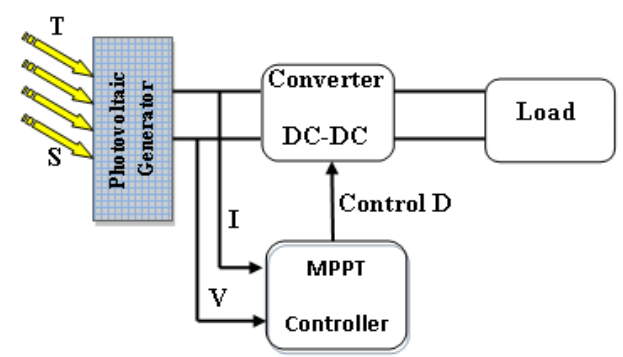

Fig. 5. Photovoltaic system.

In the following, the effectiveness of three controllers are thoroughly investigated and compared via numerical simulation.

\section{P\&O CONTROLLER}

Perturb and Observe (P\&O) technique has been selected to implement a MPPT control algorithm due to its simplicity and the possibility to introduce improvements [4], [5].

As the name suggests it is based on the perturbation of system by the increase or decrease in Vref where acting directly on the duty cycle of the converter DC-DC, then observation of the effect on the output power of the panel. If the current value of the power $P(k)$ panel is greater than the previous value $P(k-1)$ is then retains the same direction of previous disturbance or we reverse disruption of the previous cycle Fig. 6 shows the flowchart of this algorithm.

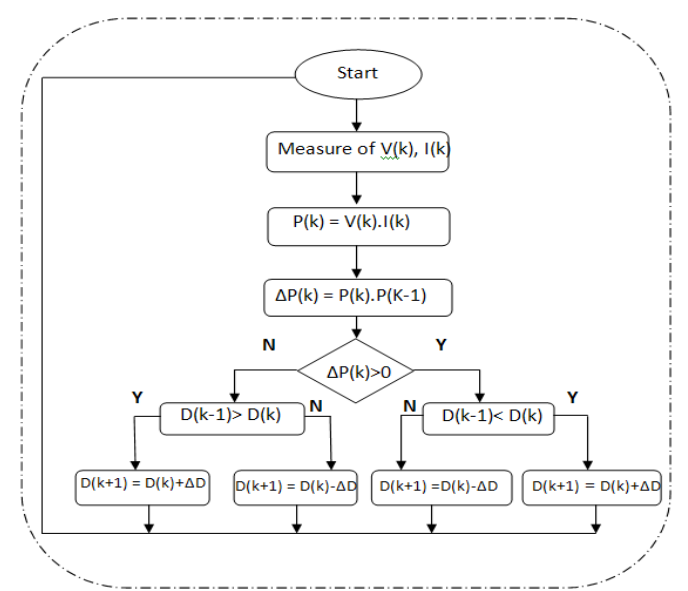

Fig. 6. Chart of the algorithm disturbance and observation (P and $\mathrm{O}$ ).

\section{INCREMENTAL CONDUCTANCE (INC)}

The incremental conductance (INC) algorithm is derived by differentiating the PV module power equation with respect to voltage and setting the result equal to zero [6], [7].

This is shown in follow Equations:

$$
P=V \times I
$$

Differentiating equation (1) with respect to $d V$ :

$$
\frac{1}{V} \frac{d P}{d V}=\frac{I}{V}+\frac{d I}{d V}=G+\Delta G
$$

From equation (2), the basic equations of this method are as follows:

$$
\begin{array}{ccc}
\frac{d P}{d V}>0 \quad \text { if } & \frac{I}{V}>-\frac{d I}{d V} \\
\frac{d P}{d V}=0 \quad \text { if } & \frac{I}{V}=-\frac{d I}{d V} \\
\frac{d P}{d V}<0 \quad \text { if } & \frac{I}{V}<-\frac{d I}{d V}
\end{array}
$$

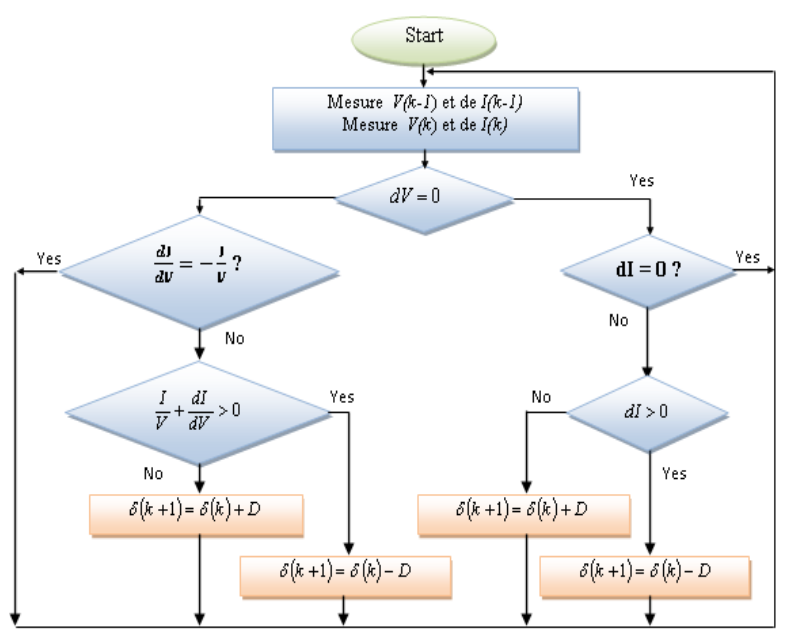

Fig. 7. Chart of the algorithm incremental conductance (INC). 
Fig. 7 shows the flow chart of the Incremental Conductance (INC) method.

\section{FUZZY LOGIC}

Fuzzy logic was introduced in 1965 with work of L. Zadeh. The latter formalizes the representation and processing of imprecise or approximate knowledge to deal with systems of great complexity or unfamiliar. Fuzzy logic is involved in the handling of imperfect knowledge, and it occurred as an effective alternative for such systems [8].

Fuzzy logic controllers (FLC) have the advantages of working with imprecise inputs, no need to have accurate mathematical model, and it can handle the non-linearity [9].

Fig. 8 shows the proposed FLC, it consists of two inputs and one output. The two FLC input variables are the error $(E)$ and change of error $(\Delta E)$ that expressed by equation (4).

$$
\left\{\begin{array}{l}
E(n)=\frac{P(n)-P(n-1)}{V(n)-V(n-1)} \\
\Delta E(n)=E(n)-E(n-1)
\end{array}\right.
$$

where $E$ and $\Delta E$ are the error and change in error, $\mathrm{n}$ is the sampling time, $P(n)$ is the instantaneous power of the PVG, and $V(n)$ is the corresponding instantaneous voltage.

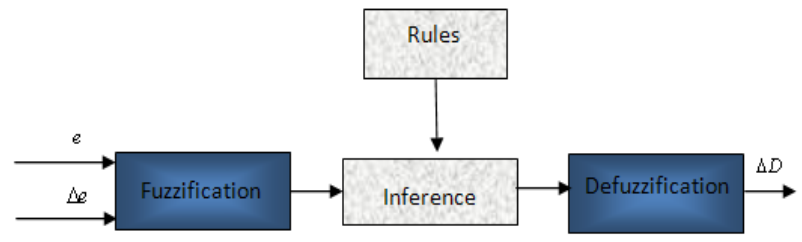

Fig. 8. Fuzzy system.

The fuzzy controller design contains the three following steps:

\section{A. Fuzzification}

The system converts the actual inputs values $\mathrm{E}$ and $\mathrm{CE}$ into linguistic fuzzy sets using fuzzy membership function. These variables are expressed in terms of five linguistic variables (such as PB (positive big), PS (positive small), ZE (zero), NB (negative big), NS (negative small) as show in Fig. 9.
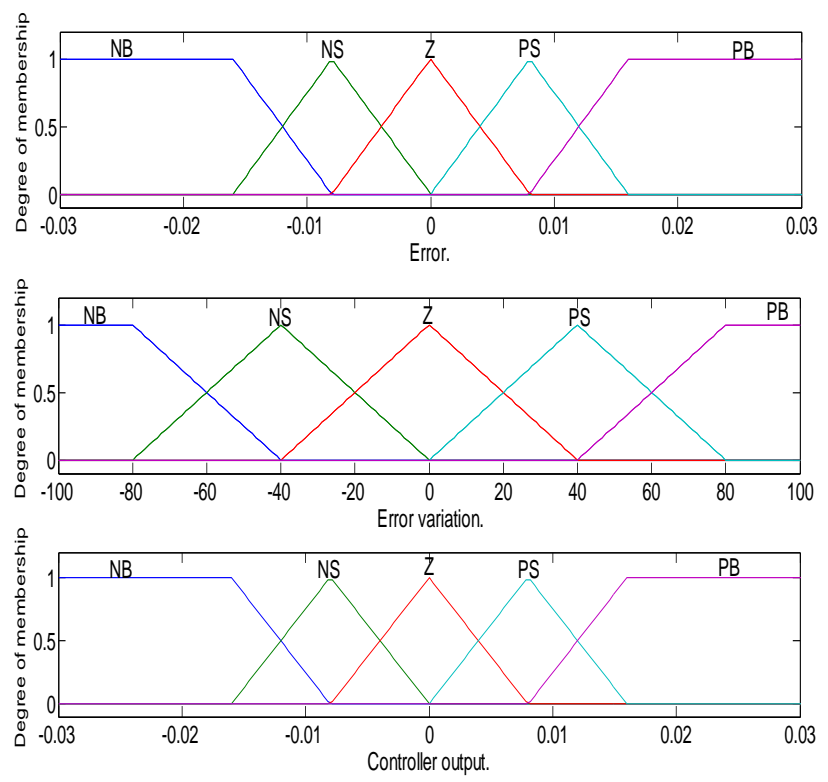

Fig. 9. Membership functions of FLC.

\section{B. Inference and Rule Base}

Inference engine is an operating method that formulates a decision based on the fuzzy rule setting and transforms the fuzzy rule base into fuzzy linguistic output. In this paper Mamdani's fuzzy inference method, with Max-Min operation has been used.

Fuzzy rule base is a collection of if-then rules that contain all the information for the controlled parameters. Table I presents the fuzzy control rules.

\section{Deffuzification}

The fuzzy logic output is converted from a linguistic variable to a numerical variable.

A fuzzy controller proposed is show in Fig. 10 [2]:

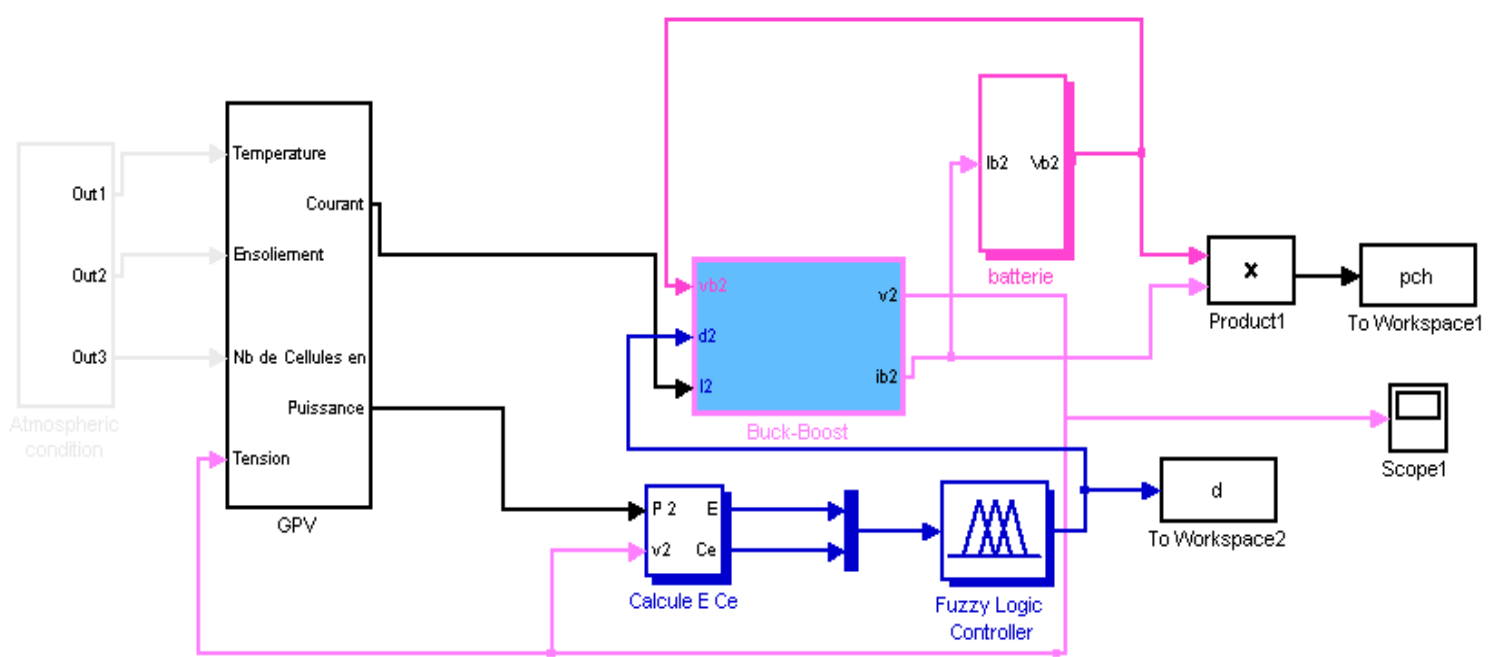

Fig. 10. Model SIMULINK of MPPT controller flou.

\section{Simulation StUdy}

Once our photovoltaic chain designed, and to verify the ability of our fuzzy controller to improve the performance obtained under the conventional MPPT controller, numerical simulation was performed for different conditions as follows: 
The first test consists to compare the performance of this controller in standard condition, solar irradiation $=1000 \mathrm{w} / \mathrm{m}^{2}$ and temperature of $25^{\circ} \mathrm{C}$. Fig. 11 shows the result of the tracked power by the two controllers.

TABLE I: FUZZY TABLE RULE

\begin{tabular}{|l|l|l|l|l|l|}
\hline $\mathbf{E} \Delta \mathbf{A E}$ & $\mathbf{N B}$ & $\mathbf{N S}$ & $\mathbf{Z E}$ & $\mathbf{P S}$ & $\mathbf{P B}$ \\
\hline $\mathbf{N B}$ & ZE & ZE & NB & NB & NB \\
\hline $\mathbf{N S}$ & ZE & ZE & NS & NS & NS \\
\hline ZE & NS & ZE & ZE & ZE & PS \\
\hline PS & PS & PS & PS & ZE & ZE \\
\hline PB & PB & PB & PB & ZE & ZE \\
\hline
\end{tabular}

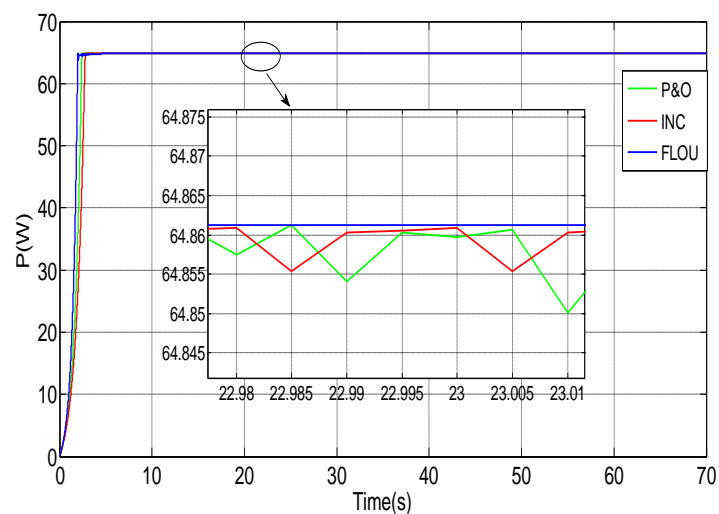

Fig. 11. Provided power from P\&O, INC tracker and FLC controller.

As can be seen, the FLC is faster than the P\&O and ICN tracker, the two controllers presents oscillations before achieve the MPP contrary to the FLC which is perfectly tuned to the maximum power point.

The next simulation is the variation of solar irradiation (from $600 \mathrm{w} / \mathrm{m}^{2}$ to $1000 \mathrm{w} / \mathrm{m}^{2}$ in $40 \mathrm{~s}$ ); the results are shown in Fig. 12.
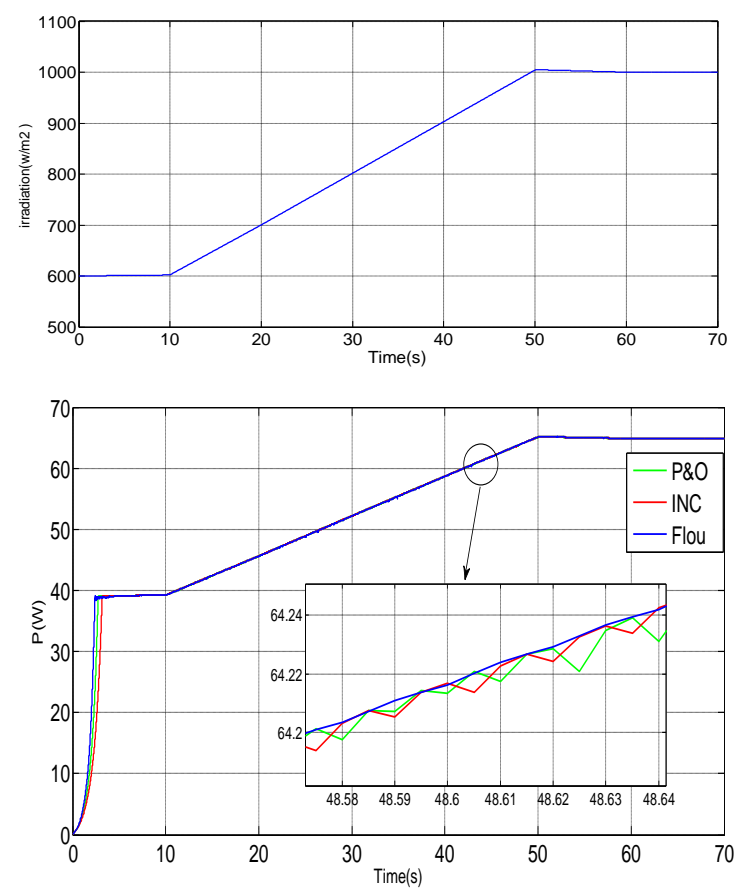

Fig. 12. Provided power in variation of irradiation.

Another simulation is under variation of temperature (increasing the temperature $25^{\circ} \mathrm{C}$ à $50^{\circ} \mathrm{C}$ in $30 \mathrm{~s}$ ) see Fig. 13.
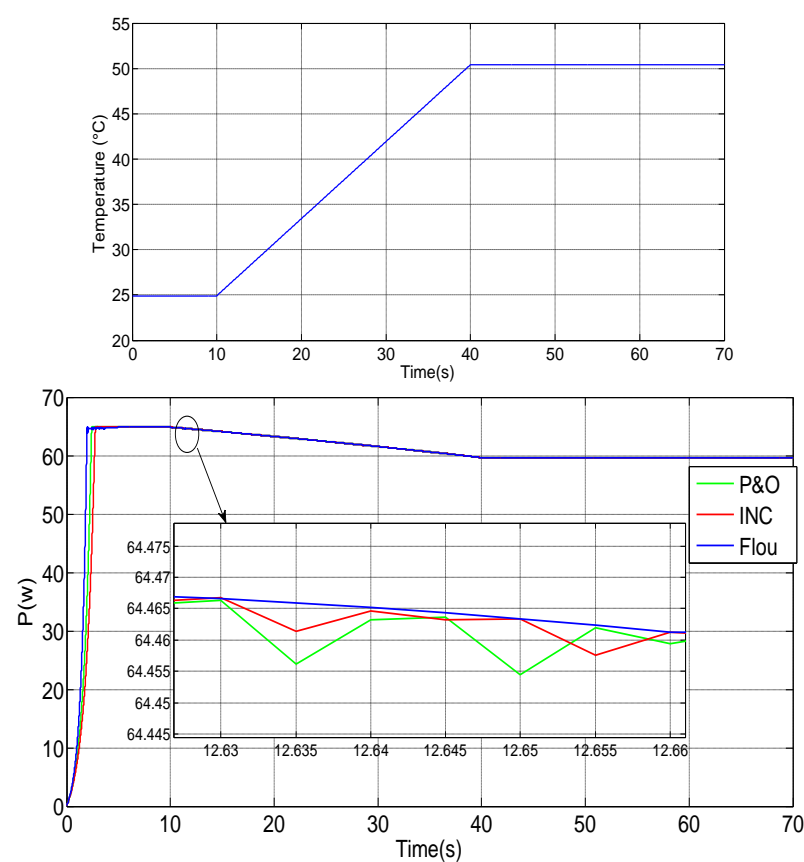

Fig. 13. Provided power in variation of temperature.

According to the tests of variation of temperature and irradiation, we notice that the fuzzy logic controller behaves exactly as expected for different variations considered contrary to the two conventional controller which presents fluctuation. In different conditions the two controllers presents overshoot and the maximum power point.

MPPT fuzzy logic controllers have been shown to perform well under varying atmospheric conditions.

\section{CONCLUSION}

In this paper we have investigated new intelligent control techniques to control output power of the solar panel in order to obtain the maximum power possible, whatever the solar irradiation and temperature conditions.

The design and simulation of two conventional (P\&O and INC) and new fuzzy logic controller based MPPT was present.

According to the obtained results we can say that use of intelligent controller to track the maximum power point in PV systems is very promising. Indeed the new controller have presents good performance: fast responses for FLC, no overshoot in permanent state.

Ongoing research, and in order to get the fast responses and no presence of fluctuations, study of introduction a genetic algorithm will be developed.

\section{REFERENCES}

[1] A. Goetzberger and V. Hoffmann, Photovoltaic Solar Energy Generation, Springer, Germany, 2005.

[2] N. Drir, L. Barazane, and M. Loudini, Fuzzy Logic for Tracking Maximum Power Point of Photovoltaic Generator, Centre de devellopement des energie renouvlables, Algeria, 2013.

[3] M. A. C. Pastor, "Conception et réalisation de modules photovoltaïques électroniques," Thèse de doctorat, Institut National des Sciences Appliquées, Toulouse, France, 2006.

[4] D. Hohm and M. Ropp, "comparative study of maximum power point tracking algorithms using an experimental, programmable, maximum power point tracking test bed," in Proc. Conference Record of the Twenty-Eighth IEEE on Photovoltaic Specialists, 2000, pp. 1699-1702.

[5] V. Salas, E. Olias, A. Barrado, and A. Lazaro, "Review of the maximum power point tracking algorithms for stand-alone 
photovoltaic systems," Solar Energy Materials and Solar cells, vol. 90, no. 3, pp. 329-340, 2006.

[6] K. H. Hussein and G. Zhao, "Maximum photovoltaic power tracking: an algorithm for rapidly changing atmospheric condition," IEEE Proceedings of Generation, Transmission, Distribution, vol. 142, no. 1, pp. 59-64, 1995

[7] B. Liu, S. Duan, F. Liu, and P. Xu, "Analysis and improvement of maximum power point tracking algorithm based on incremental conductance method for photovoltaic array," in Proc. IEEE PEDS, 2007, pp. 637-641.

[8] D. Graham and R. C. Lathrop, "The synthesis of optimum transient response: criteria and standard forms," Transactions of the American Institute of Electrical Engineers, Part 2: Applications and Industry, vol. 72, pp. 273-288, 1953.

[9] S. Amamra, Commande par Réseaux de neurones d'une Machine Asynchrone avec Linéarisation Hybride, Magister Memory, ENP, Algiers, 2005.

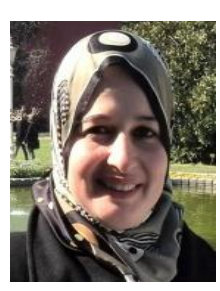

N. Drir was born in Algiers on July 19, 1984. She has obtained her magister degree at Electronic University of Sciences and Technology Houari Boumediene of Algiers. She is working towards her doctorate degree. Her research interests include modeling new intelligent control to track maximum power point in the photovoltaic system. Nadia is working as a core transmission networking expert at a Mobile Operator in Algiers. She is in charge of transmission backbone and backhaul engineering.

L. Barazane received the engineer degree in electrical engineering from University of Science and Technology Houari Boumediene (USTHB) and the master grade in power electronics and process control from the national polytechnic school of Algiers (ENPA), Algeria in 1993. She received the $\mathrm{PhD}$ degree in automatic from ENP in 2003. Since 1993, she holds a teaching and research position at the Department of Electrical Engineering, Electronic and Informatics Faculty, USTHB, Algeria, where she is currently a professor and the head of the team "control, supervision and diagnostic of electrical processes of the laboratory (LSEI). Her research interests are electrical drives, nonlinear control, variable structure control and application of artificial intelligence in control processes.

M. Loudini is an associate professor in automatic control and the director of Research at the École Nationale Supérieure d'Informatique of Algiers. He received his doctorat d'État (Ph.D. degree) in automatic control from the École Nationale Polytechnique of Algiers in 2007. His research interests include modeling and intelligent control of engineering and computing systems. 